http://dx.doi.org/10.11646/phytotaxa.203.3.7

\title{
Further examination of the geographic range of Eriogonum corymbosum var. nilesii (Polygonaceae, Eriogoneae)
}

\author{
MARK W. ELLIS ${ }^{1,5}$, PAUL G. WOLF ${ }^{1,4}$, SHANNON BARDOT ${ }^{2}$, JAMES A. WALTON ${ }^{2}$, CAROL A. ROWE $^{1}$, SARAH \\ KULPA $^{3}$ \& KAREN E. MOCK ${ }^{2,4}$. \\ ${ }^{I}$ Department of Biology, Utah State University, Logan, UT, 84322, U.S.A. \\ ${ }^{2}$ Utah State University, S.J. \& Jessie E. Quinney College of Natural Resources, Wildland Resources Department, Logan, UT, 84322, \\ U.S.A. \\ ${ }^{3}$ Nevada Fish and Wildlife Office, 1340 Financial Boulevard, Suite 234, Reno, NV, 89502, U.S.A. \\ ${ }^{4}$ Ecology Center, Utah State University, Logan, UT, 84322, U.S.A. \\ ${ }^{5}$ Author for correspondence: mark.ellis@usu.edu.
}

\begin{abstract}
The wild buckwheat Eriogonum corymbosum is widely distributed throughout the southwestern United States, forming a complex of eight varieties. E. corymbosum var. nilesii is a predominantly yellow-flowered variant reported primarily from Clark Co., Nevada. A previous genetic study by our research group found that var. nilesii is genetically distinct from other E. corymbosum varieties, based on a limited number of populations. Here, we assess genetic variation in 14 newly sampled yellow-flowered populations from southern Nevada, southern Utah, and northern Arizona, and compare them to genetic variation in six populations of previously determined E. corymbosum varieties. Of the new populations, we identified four as var. nilesii, four as var. aureum, three as var. glutinosum, two as apparent hybrids involving vars. aureum and nilesii, and one as a more distantly related admixture involving E. thompsoniae. Our results extend the range and area of E. corymbosum var. nilesii considerably from that traditionally stated in the literature. However, this extended range is confined to the Mojave Desert region of southern Nevada, and the number of known populations remains limited.
\end{abstract}

Key words: conservation genetics, Eriogonum, population genetics, U.S.A.

\section{Introduction}

Eriogonum corymbosum Bentham (1856: 17) (Polygonaceae Juss., Eriogoneae Dumort.) is a wild buckwheat species native to and widely distributed throughout the southwestern United States. Across its range, these woody shrubs vary in size, leaf shape and surface structure, flower color, overall habit, and ecology, forming a complex of eight varieties (Reveal 2002, 2005, 2014). Three varieties_-var. nilesii Reveal (2004: 128), var. aureum (M.E. Jones [1895: 718]) Reveal (1982: 293), and var. glutinosum [M.E. Jones (1895: 719)] M.E. Jones (1903: 14)—are predominantly yellowflowered, and these have historically been confused with one another (Reveal 2002). E. corymbosum var. nilesii (Niles's wild buckwheat) has traditionally been viewed as having a patchy distribution confined to Clark Co., Nevada (Reveal 2004), mainly in and around Las Vegas, while var. aureum was thought to be confined to a single population in Washington Co., Utah (Reveal 2005, 2012, 2013), and var. glutinosum was considered widely distributed throughout southern Utah and northern Arizona (Reveal 2002, 2005, 2009, 2012, 2013).

Concerns about the potential rarity of E. corymbosum var. nilesii, with its patchy distribution and limited known range in southern Nevada, along with questions about whether phenotypically similar populations in northwestern Arizona and southwestern Utah were var. nilesii, led to a study by Ellis et al. (2009). Genetic markers were used to examine populations of the six varieties and closely related species. The results of that study suggested that var. nilesii was relatively distinct genetically and (based on the populations tested) confined to the Mojave Desert in Clark Co., Nevada. Data from Ellis et al. (2009) also supported the separation of the three predominantly yellow-flowered $E$. corymbosum varieties described by Reveal (2005) as var. glutinosum, var. aureum, and var. nilesii. 
In addition, Ellis et al. (2009) found that predominantly yellow-flowered E. corymbosum populations sampled in and around St. George, Washington Co., Utah, grouped genetically with the single known population of var. aureum, thus expanding the range of that taxon from that indicated by Reveal $(2005,2012,2013)$. They also found that var. aureum was the taxon most closely related to var. nilesii, hypothesizing that the region of southwestern Utah was a zone of hybridization in which some populations of var. aureum were introgressed by var. nilesii. This region is also a transition zone between the Mojave Desert, which encompasses Nevada's Clark Co. populations of var. nilesii, and the southwestern portion of the Colorado Plateau where var. aureum resides.

Since 2009, additional yellow-flowered E. corymbosum populations have been found that are difficult to assign taxonomically based on morphological and ecosystem characteristics. Some of these populations appear phenotypically similar to var. nilesii. If they are indeed var. nilesii, this would expand that taxon's known range into Lincoln Co., Nevada, as well as into regions of northern Arizona and southern Utah (fide Reveal 2013). Such a broad range extension might influence listing and management decisions by federal and state agencies. Our aims were to sample these additional E. corymbosum populations that are phenotypically similar to var. nilesii in a region comprising the borders of northern Arizona, southern Nevada, and southern Utah and compare them genetically to reference populations of known E. corymbosum varieties in order to determine their taxonomic identities (Fig. 1, Table 1).

\section{Materials and Methods}

Twenty Eriogonum populations, including all 14 of the newly found yellow-flowered populations (Fig. 1, Table 1) were sampled in the spring of 2012. The additional six populations collected were reference populations examined previously by Ellis et al. (2009). Each collection site comprised a geographically bounded and relatively isolated group of potentially interbreeding individuals. Twenty plants were sampled per population, with $10-15$ leaves per plant placed within a folded coffee filter in a zip-locking plastic bag with silica gel desiccant for DNA preservation. Voucher specimens were collected at all sites (see Table 1) and deposited at the Intermountain Herbarium (UTC, acronym according to Thiers 2011).

TABLE 1. Sample sites of Eriogonum populations collected in 2012. Named taxa are site identifications in Ellis et al. (2009), used here as reference populations.

\begin{tabular}{|c|c|c|c|c|}
\hline Pop \# & Site Name (state) & Taxon & Latitude & Longitude \\
\hline P01 & Glen Canyon (AZ) & Newly sampled & 36.9367465 & -111.4930038 \\
\hline $\mathrm{P} 02$ & Divide (UT) & Newly sampled & 37.0442458 & -113.2722247 \\
\hline P03 & Ft. Pierce (AZ) & Newly sampled & 36.9944193 & -113.4530931 \\
\hline P04 & Ft. Pierce Road (UT) & Newly sampled & 37.0200578 & -113.3195412 \\
\hline P05 & Long Canyon (UT) & Newly sampled & 37.0754888 & -111.9468535 \\
\hline P06 & Blue Pool Wash (UT) & Newly sampled & 37.0385448 & -111.6182841 \\
\hline P07 & $\mathrm{S} 36 \mathrm{AZ}(\mathrm{AZ})$ & Newly sampled & 36.9045085 & -113.5601964 \\
\hline P08 & Badlands (UT) & Newly sampled & 37.2081548 & -113.2314430 \\
\hline P09 & GB1 (NV) & Newly sampled & 36.3011199 & -114.1566169 \\
\hline $\mathrm{P} 10$ & Muddy (NV) & Newly sampled & 36.2289158 & -114.6919300 \\
\hline $\mathrm{P} 11$ & Toq Wash (NV) & Newly sampled & 36.9692713 & -114.2145968 \\
\hline P12 & WB2 (NV) & Newly sampled & 36.2622885 & -114.5586741 \\
\hline $\mathrm{P} 13$ & Coyote Springs (NV) & Newly sampled & 36.7729489 & -114.9188983 \\
\hline $\mathrm{P} 14$ & CTA1 (NV) & E. corymbosum nilesii & 36.3038320 & -115.1622041 \\
\hline P15 & GB2 (NV) & Newly sampled & 36.4762215 & -114.1591554 \\
\hline P16 & A01 (AZ) & E. corymbosum glutinosum & 36.8369400 & -111.5083300 \\
\hline $\mathrm{P} 17$ & U01 (UT) & E. corymbosum aureum & 37.1836100 & -113.7675000 \\
\hline P18 & U11 (UT) & E. corymbosum orbiculatum & 37.7497200 & -111.4436100 \\
\hline P19 & U13 (UT) & E. corymbosum corymbosum & 38.2511100 & -111.3741700 \\
\hline $\mathrm{P} 20$ & $\mathrm{U} 33$ (UT) & E. thompsoniae & 37.1396700 & -113.2499800 \\
\hline
\end{tabular}

The following collection protocol was followed to avoid bias in the sample-selection process. After surveying a given site to determine the general boundaries of a population, a central transect was marked through the length of the population. Plants were sampled along that transect that were at least $5 \mathrm{~m}$ apart (to avoid resampling clones). If too few plants were sampled following this method, plants were sampled further from the transect, again ensuring they were at least $5 \mathrm{~m}$ from any other sampled plant. Plants were not selected based on size, apparent age, or other morphological features. 
DNA was extracted using the Qiagen DNeasy Plant kit following the manufacturer's protocols. Dried leaf tissue was ground in a Tissuelyser II (Qiagen Inc., Valencia, CA) with tungsten carbide beads. The final DNA product was eluted from each column into $100 \mu \mathrm{l}$ of AE buffer (Qiagen Inc., Valencia, CA).

In our first attempt to acquire genetic markers, we used microsatellite primers developed for Eriogonum giganteum S.Watson (1885: 371) by Riley et al. (2011). However, none of the 12 primer sets produced reliable or informative genotypes across the varieties of $E$. corymbosum being investigated. Therefore, we switched to an amplified fragment length polymorphism (AFLP) analysis; a restriction-based assay. AFLP methods were based on Vos et al. (1995) and modified by Ellis et al. (2009) and by Kettenring \& Mock (2012). We used seven different combinations of 3nucleotide selective primers. The amplified restriction fragments were separated via capillary electrophoresis and recorded using Applied Biosystem's ABI 3730 DNA Analyzer with a LIZ-500 size standard.

AFLP profiles were visualized and scored using Genographer v1.6.0 (Benham 2001). We replicated 80 (17\%) of the samples (from two to seven times each) to determine the reliability and error rates in band scoring. We also developed samples with no DNA template, from the extraction phase forward, and included them in 12 to 14 lanes per $\mathrm{ABI}$ run to act as negative controls.

For each sample, presence and absence of a band was scored as " 1 " and " 0 " respectively. Two people scored the data independently and any detected mismatches were reconciled with further visual inspection of the gel data. Next, any locus with more than three mismatches among replicates (within one primer combination) was removed from the dataset. Data from the seven primer combinations were then concatenated by individual into a single file and converted to GenAlEx 6.501 (Peakall \& Smouse 2006, Peakall \& Smouse 2012) format. Custom Python scripts were used for all data manipulations (https://github.com/Wolflab/AFLPs).

We examined genetic relationships among individuals and populations by analyzing the AFLP data with principal coordinates analysis (PCoA) within GenAlEx. PCoA is a method to qualitatively explore and visualize clustering among individual samples without regard to population identity. Population identity is not considered in the analysis and does not affect clustering.

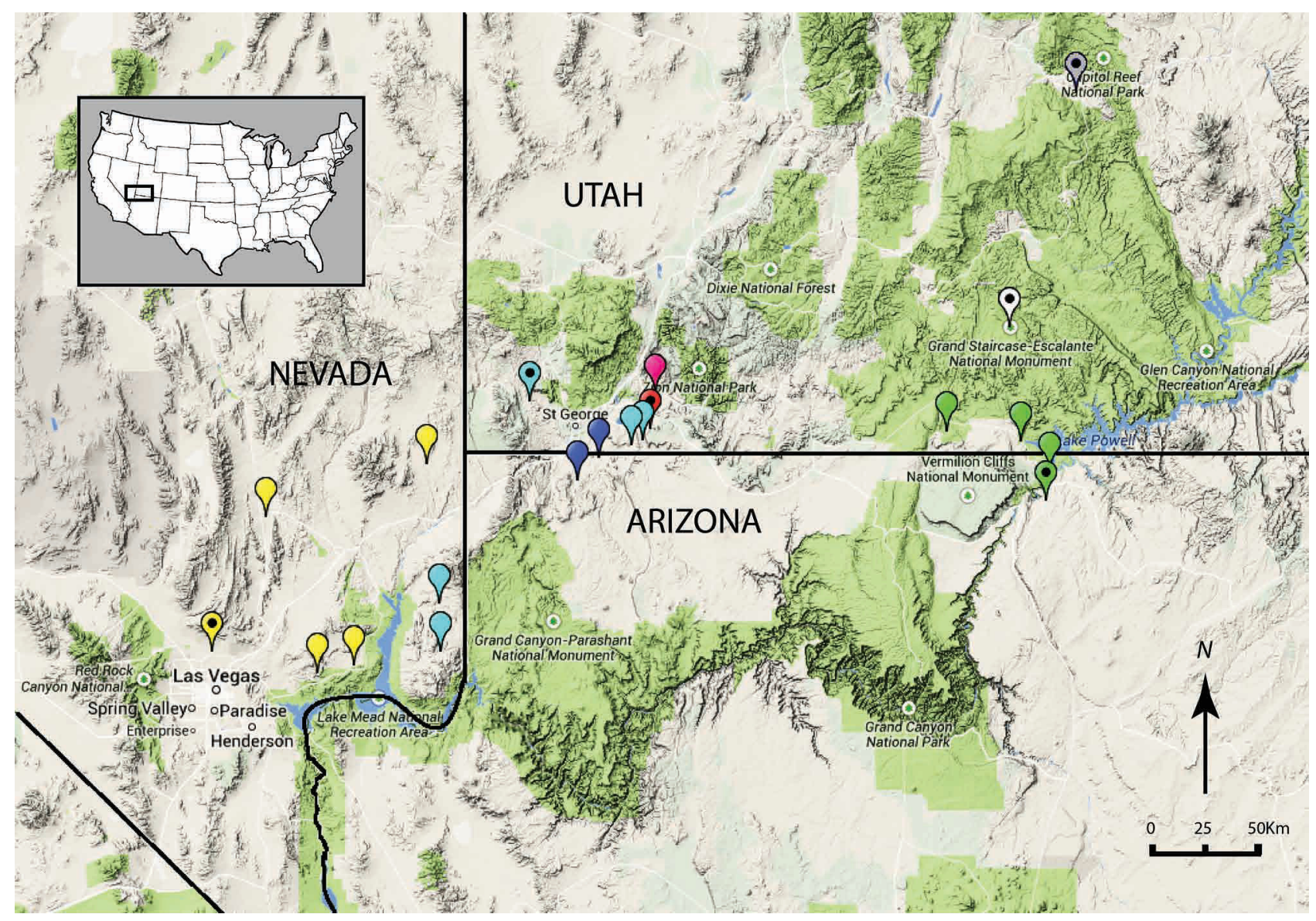

FIGURE 1. Sample-site locations (see Table 2). Taxonomic designations are based on our findings: yellow = Eriogonum corymbosum var. nilesii, turquoise $=$ var. aureum, green $=$ var. glutinosum, white $=$ var. orbiculatum, gray $=$ var. corymbosum, blue $=$ admixed population involving vars. aureum and nilesii, red $=$ E. thompsoniae, and pink = Badlands population. Each site icon with a black dot is a reference population. 
We also used the computer program STRUCTURE 2.3.4 (Falush et al. 2003, Falush et al. 2007, Hubisz et al. 2009, Pritchard et al. 2000) to perform individual-based assignment tests. STRUCTURE uses a Bayesian, modelbased approach to assess population structure for multilocus data, including dominant markers such as AFLPs. In the analysis reported here we assumed correlated allele frequencies and admixed ancestry, with a burn-in of 20,000 followed by 10,000 iterations. We tested 1-10 clusters ( $K$-values), with ten iterations for each number of clusters. The most probable $K$-value was determined following the delta-K method of Evanno et al. (2005) using the online version of STRUCTURE HARVESTER 0.6.9.1 (Earl \& vonHoldt 2012).

TABLE 2. Newly sampled populations grouped with their associated reference populations.

\begin{tabular}{|c|c|c|c|}
\hline & Pop\# & Site name & Taxon \\
\hline \multirow[t]{5}{*}{ var. nilesii group } & P14 & CTA1 (ref pop) & E. corymbosum var. nilesii \\
\hline & $\mathrm{P} 10$ & Muddy & Newly sampled \\
\hline & P11 & Toq Wash & Newly sampled \\
\hline & $\mathrm{P} 12$ & WB2 & Newly sampled \\
\hline & P13 & Coyote Springs & Newly sampled \\
\hline \multirow[t]{5}{*}{ var. aureum group } & P17 & U01 (ref pop) & E. corymbosum var. aureum \\
\hline & $\mathrm{P} 02$ & Divide & Newly sampled \\
\hline & P04 & Ft. Pierce Road & Newly sampled \\
\hline & P09 & GB1 & Newly sampled \\
\hline & P15 & GB2 & Newly sampled \\
\hline \multirow[t]{4}{*}{ var. glutinosum group } & P16 & A01 (ref pop) & E. corymbosum var. glutinosum \\
\hline & $\mathrm{P} 01$ & Glen Canyon & Newly sampled \\
\hline & P05 & Long Canyon & Newly sampled \\
\hline & P06 & Blue Pool Wash & Newly sampled \\
\hline \multirow[t]{2}{*}{ Admixed aureum/nilesii group } & $\mathrm{P} 03$ & Ft. Pierce & Newly sampled \\
\hline & $\mathrm{P} 07$ & A36AZ & Newly sampled \\
\hline \multirow[t]{4}{*}{ Other taxa } & P08 & Badlands & Newly sampled \\
\hline & P18 & U11 (ref pop) & E. corymbosum var. orbiculatum \\
\hline & P19 & U13 (ref pop) & E. corymbosum var. corymbosum \\
\hline & $\mathrm{P} 20$ & U33 (ref pop) & E. thompsoniae \\
\hline
\end{tabular}

\section{Results}

The final AFLP data set contained 457 individuals (excluding replicates) and 105 AFLP loci. Error rates were 0.97\%, based on mismatches across replicated samples. AFLP genotype data are available from Digital Commons (http://digitalcommons. usu.edu/all_datasets/3/).

A population-level PCoA analysis shows clear separation among most of the populations studied, with the first two axes explaining $62.6 \%$ of the variance. PCoA analyses of individuals (Figs. 2-3) demonstrate the same populationlevel separation. The variation explained by the first two axes in the individual-level PCoAs is lower (45.1\%) as expected when inter-individual variation (within populations) is included.

Figure 2 reveals that the reference populations for E. thompsoniae S.Watson (1873: 302), E. corymbosum var. orbiculatum (S. Stokes [1936: 79]) Reveal \& Brotherson (Reveal 1968: 221), and var. corymbosum (populations P20, P18, P19 respectively) form three distinct clusters. The reference population for var. glutinosum (P16) forms a distinct cluster that includes individuals from the newly sampled populations Glen Canyon (P01), Long Canyon (P05), and Blue Pool Wash (P06). Individuals from the newly collected population Badlands (P08) form a cluster between the reference population for E. thompsoniae (P20) and a cluster containing the reference populations for E. corymbosum var. aureum (P17) and var. nilesii (P14) along with members of the remaining newly sampled populations. This aureumnilesii cluster required closer inspection with a PCoA analysis of only those samples.

The PCoA analysis of the subset of samples representing E. corymbosum var. aureum and var. nilesii, and the 10 remaining newly sampled populations that clustered with them in Figure 2, shows two clusters that partially overlap 
(Fig. 3). The populations Divide (P02), Ft. Pierce Road (P04), GB1 (P09), and GB2 (P15) all grouped with var. aureum, while populations Muddy (P10), Toq Wash (P11), WB2 (P12), and Coyote Springs (P13) all grouped with var. nilesii. Those populations in the overlapping area of the two clusters were Ft. Pierce (P03) and S36AZ (P07).

In the STRUCTURE analysis of the 14 populations (Fig. 4), a $K$-value of 4 was determined to be the most likely population structure. This analysis corroborates the PCoA findings, but in addition, two populations (P03 and P07) show genetic admixture likely due to apparent hybridization between var. aureum and var. nilesii. Although the STRUCTURE profile for the reference population P17 is primarily var. aureum, it demonstrates some introgression from var. nilesii and E. thompsoniae.

\section{Principle Coordinates (PCoA) - All Populations}

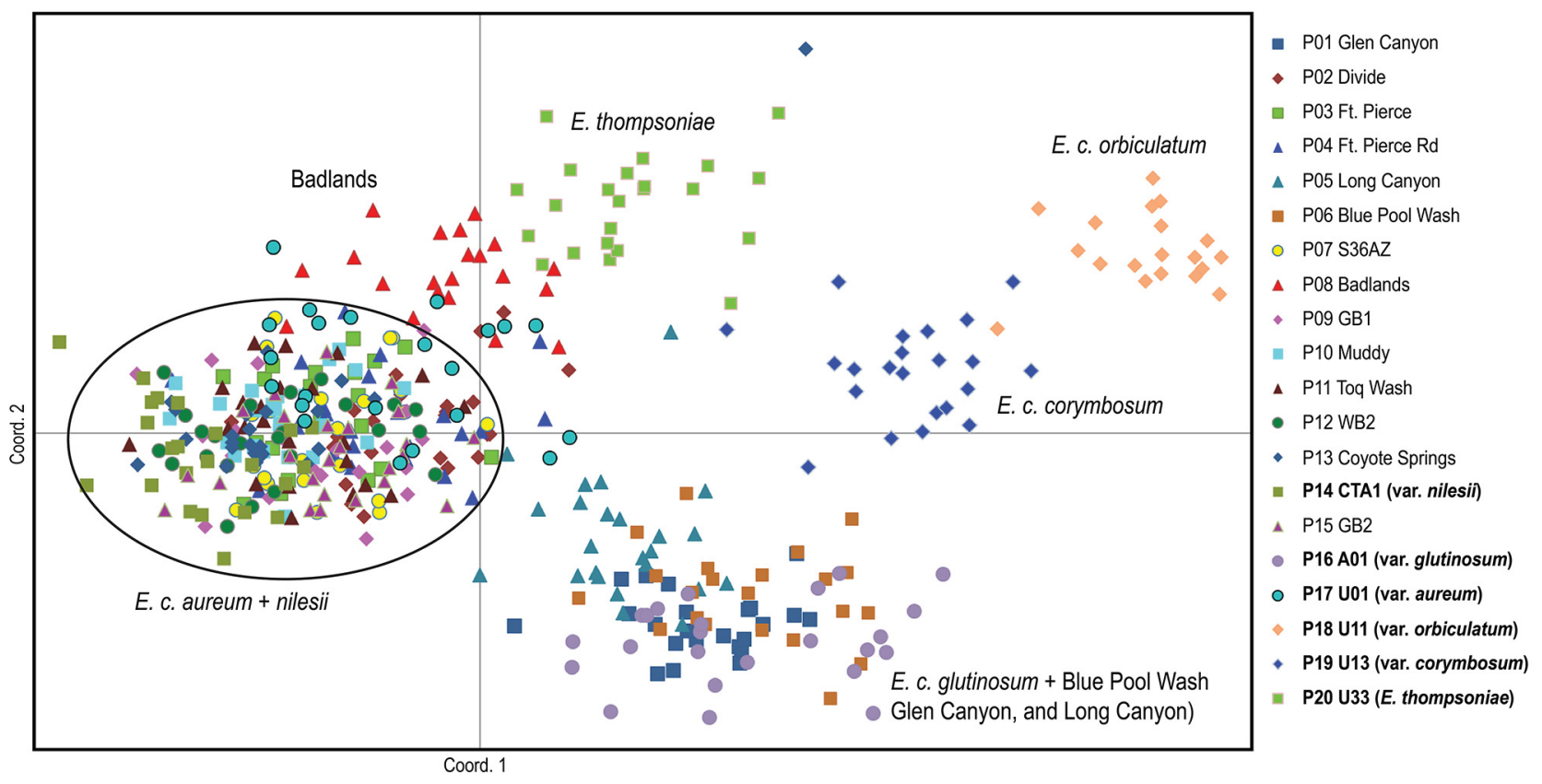

FIGURE 2. Principle Coordinates Analysis of all populations. Those circled compose a cluster of samples closely associated with (and including) the reference populations for Eriogonum corymbosum vars. nilesii and aureum.

\section{Discussion}

Populations of Eriogonum corymbosum in Clark Co., Nevada, were previously determined to be var. nilesii based on morphology, geography, and ecology (Reveal 2004), as well as genetic analyses (Ellis et al. 2009). In 2009, the known range of this taxon was limited to Clark Co.'s Las Vegas Valley and a single population in White Basin, with reports of one or two other sites presumed to be var. nilesii.

On the basis of the present study, the two predominantly white-flowered varieties of $E$. corymbosum that we tested (var. corymbosum and var. orbiculatum) were more closely related to each other than to any of the yellow flowered populations examined (Fig. 2). Although flower color can vary from white to yellow in some E. corymbosum varieties (Ellis et al. 2009; Reveal 2002, 2005, 2012, 2013), these findings suggest that predominant flower color can be a useful trait for identifying entities in the field if used in combination with other phenotypic characteristics.

Of the three E. corymbosum varieties that are predominantly yellow-flowered, our results suggest populations of var. glutinosum are genetically distinct from populations of vars. nilesii and aureum, as well as from all other populations tested (Fig. 2). Our results also suggest that var. glutinosum is more closely related to var. aureum than to var. nilesii (Fig. 2).

Our assignments of the two newly sampled populations P2 and P4 to var. aureum are consistent with the findings of Ellis et al. (2009) that many of the yellow-flowered populations of E. corymbosum encountered in Washington Co., Utah, are var. aureum (Figs. 1, 3, and 4). These findings also demonstrate that var. aureum is the expression most closely related to var. nilesii. Two additional newly-sampled populations (P09 and P15) determined to be var. aureum expand the known range of that variety beyond Washington Co., south and west onto the Mojave Desert region of Clark Co., Nevada, east of the northern extension of Lake Mead (Fig. 1). These populations were previously considered to be var. nilesii by Reveal $(2011,2014)$. 
Principle Coordinates: E. corymbosum vars. nilesii and aureum with closely related newly-sampled populations

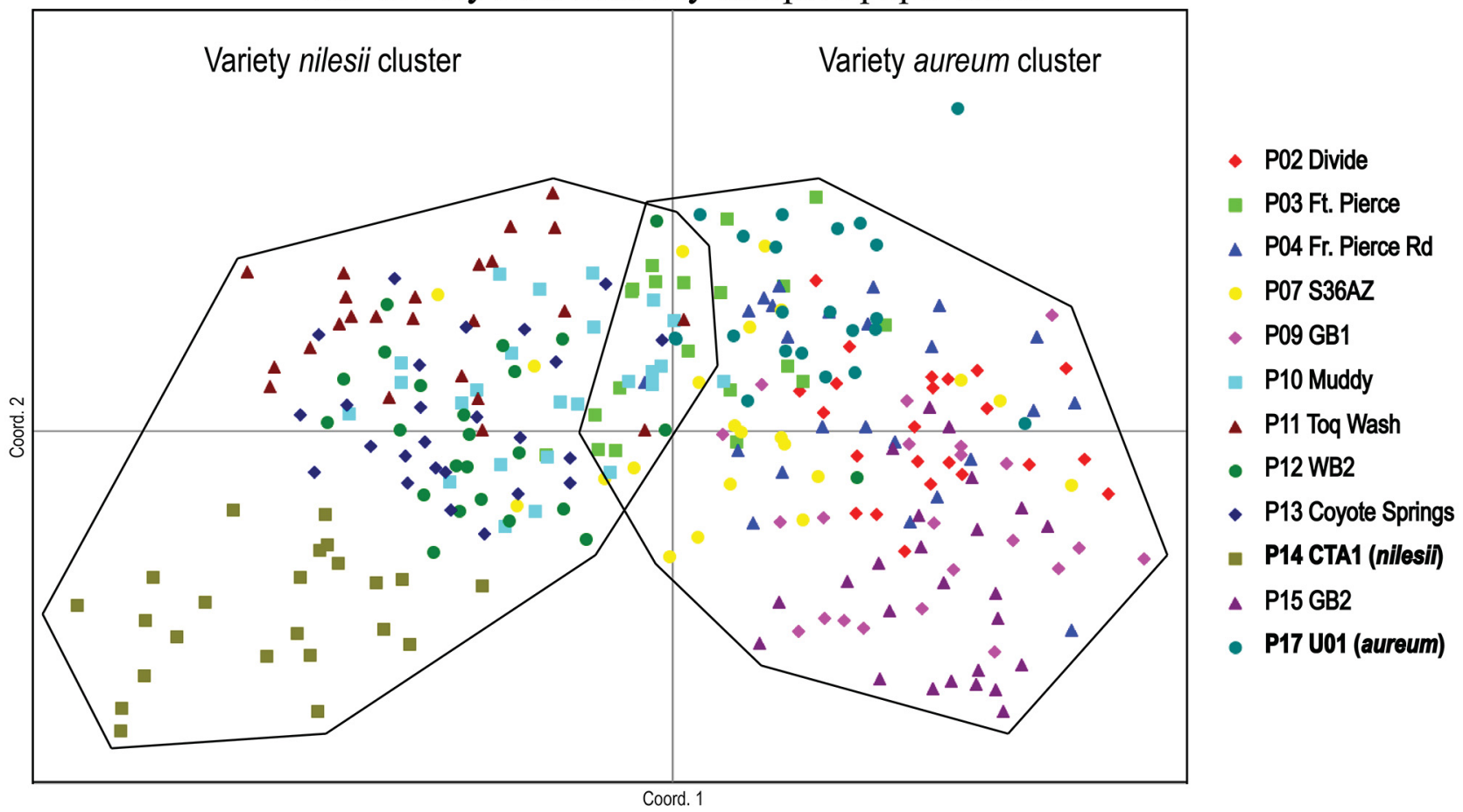

FIGURE 3. Principle Coordinates Analysis showing populations in two clusters, with those most closely associated with (and including) the reference population for Eriogonum corymbosum var. nilesii on the left, and those most closely associated with (and including) the reference population for E. corymbosum var. aureum on the right.

We found evidence that hybridization between vars. aureum and nilesii has occurred in an ecotonal transition zone between the Colorado Plateau and the Mojave Desert. This is demonstrated in populations P03 and P07, found in the border region between southwestern Utah and northwestern Arizona (Figs. 1 and 4). Additionally, the reference population for E. corymbosum var. aureum (P17) is also located in this transition zone on the Shivwits Reservation in Washington Co., Utah (Fig. 1, Table 1). That population, once considered the only population of var. aureum (Reveal 2005, 2012, 2013), appears to be introgressed by var. nilesii and E. thompsoniae (Fig. 4). This introgression might explain the phenotypic variation that led Reveal (2005) to consider this single population to be a separate variety especially since E. thompsoniae is not known to occur on the Shivwits Reservation. However, our results here and those of Ellis et al. (2009) establish it as var. aureum, along with many other predominantly yellow-flowered $E$. corymbosum populations in Washington Co., Utah.

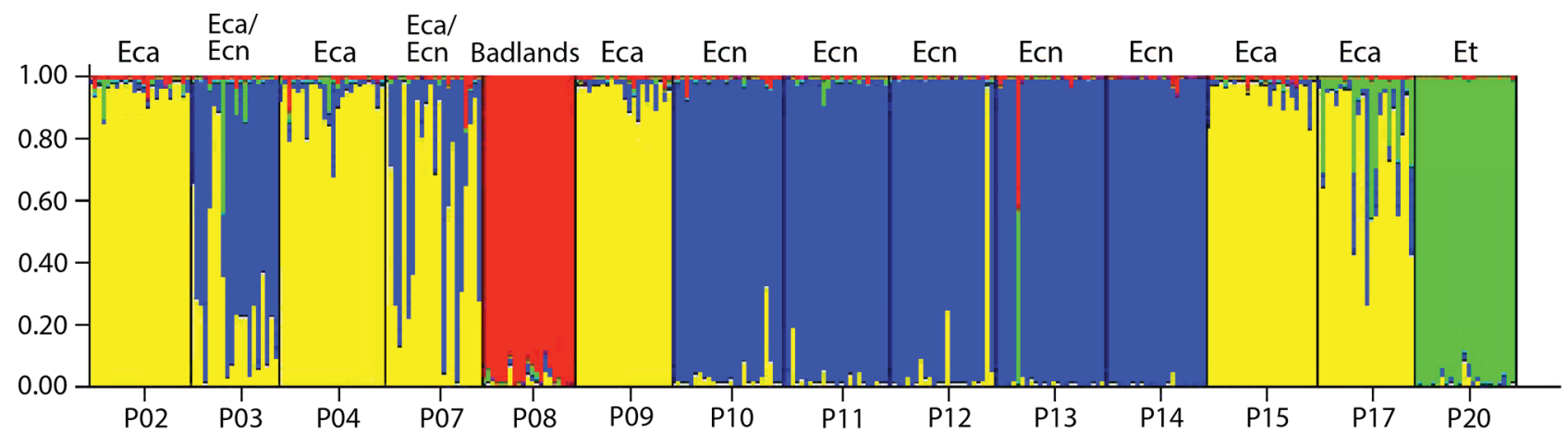

FIGURE 4. STRUCTURE 2.3.4 bar graph of 14 populations with color-coded assignments to four clusters. The inferred taxonomic assignments (based on predominant color coding) are listed above each population set. Blue corresponds to Eriogonum corymbosum var. nilesii, yellow to E. corymbosum var. aureum, green for E. thompsoniae, and red (the Badlands population) is not clearly associated with the other taxa. Each vertical bar represents an individual, with proportions of the 4 colors in each based on AFLP profiles. 


\section{Conclusion}

Until now, the known range of Eriogonum corymbosum var. nilesii was limited to Clark Co., Nevada populations in and around Las Vegas and in White Basin (a single population west of the northern extension of Lake Mead). In this study, we identified four additional populations as var. nilesii (Fig. 4). Two of these four newly sampled populations (P10 and P12) extend the known geographic range of var. nilesii further south into the Muddy Mountains and White Basin region west of the Virgin River and Lake Mead, while the other two populations (P13 to the northwest in Clark Co. and P11 to the northeast in Lincoln Co.) extend the range considerably further north (Fig. 1). Although large in area, this expanded range for var. nilesii remains confined to the Mojave Desert region of southern Nevada, and there are fewer than ten known populations outside of Las Vegas Valley, each of which is limited in area. With the few remaining sites of E. corymbosum var. nilesii in and around Las Vegas at risk of extirpation by development, the taxon appears to be vulnerable. Without additional and well-planned field surveys of the region bounded by these populations, E. corymbosum var. nilesii should be considered rare.

\section{Acknowledgements}

The research reported here was funded by cooperative agreements with US Fish and Wildlife Service and the Nevada Division of Forestry. Thanks also to Katelin Madsen for lab assistance, to Michael Piep and Sara Lamb for voucher specimen curation, and to James Reveal (Ithaca) and an anonymous reviewer for their useful comments and suggestions.

\section{References}

Bentham, G. 1856. Eriogoneae. In: Candolle, A.P. de (Ed.) Prodromus Systematis Regni Vegetabili, vol. 14. V. Masson. Paris, pp. 5-28. Benham, J.J. (2014) Genographer Version 1.6.0. Available from: http://genographer.sourceforge.net/.

Earl, D.A. \& von Holdt, B.M. (2012) STRUCTURE HARVESTER: A website and program for visualizing STRUCTURE output and implementing the Evanno method. Conservation Genetics Resources 4: 359-361. http://dx.doi.org/10.1007/s12686-011-9548-7

Ellis, M.W., Roper, J.M., Gainer, R., Der, J.P. \& Wolf, P.G. (2009) The taxonomic designation of Eriogonum corymbosum var. nilesii (Polygonaceae) is supported by AFLP and cpDNA analyses. Systematic Botany 34: 693-703. http://dx.doi.org/10.1600/036364409790139736

Evanno, G., Regnaut, S. \& Goudet, J. (2005) Detecting the number of clusters of individuals using the software STRUCTURE: A simulation study. Molecular Ecology 14: 2611-2620. http://dx.doi.org/10.1111/j.1365-294X.2005.02553.x

Falush, D., Stephens, M. \& Pritchard, J.K. (2003) Inference of population structure using multilocus genotype data: Linked loci and correlated allele frequencies. Genetics 164: 1567-1587. http://www.genetics.org/content/164/4/1567.full.pdf + html

Falush, D., Stephens, M. \& Pritchard, J.K. (2007) Inference of population structure using multilocus genotype data: Dominant markers and null alleles. Molecular Ecology Notes 7: 574-578. http://dx.doi.org/10.1111/j.1471-8286.2007.01758.x

Hubisz, M.J., Falush, D., Stephens, M. \& Pritchard, J.K. (2009) Inferring weak population structure with the assistance of sample group information. Molecular Ecology Resources 9: 1322-1332. http://dx.doi.org/10.1111/j.1755-0998.2009.02591.x

Kettenring, K.M. \& Mock, K.E. (2012) Genetic diversity, reproductive mode, and dispersal differ between the cryptic invader, Phragmites australis, and its native conspecific. Biological Invasions 14: 2489-2504. http://dx.doi.org/10.1007/s10530-012-0246-5

Jones, M.E. (1895) Contributions to western botany. No. VII. Proceedings of the California Academy of Sciences, ser. II, 5: 611-733.

Jones, M.E. (1903) Contributions to western botany. Contributions to Western Botany 11: 1-22.

Peakall, R. \& Smouse, P.E. (2006) GENALEX 6: Genetic analysis in Excel. Population genetic software for teaching and research. Molecular Ecology Notes 6: 288-295. http://dx.doi.org/10.1111/j.1471-8286.2005.01155.x 
Peakall, R. \& Smouse, P.E. (2012) GenAlEx 6.5: Genetic analysis in Excel. Population genetic software for teaching and research—an update. Bioinformatics 28: 2537-2539. http://bioinformatics.oxfordjournals.org/content/28/19/2537

Pritchard, J.K., Stephens, M. \& Donnelly, P. (2000) Inference of population structure using multilocus genotype data. Genetics 155: 945-959. Available from: http://www.genetics.org/content/155/2/945.

Reveal, J.L. (1968) Notes on Eriogonum - V. A revision of Eriogonum corymbosum complex. Great Basin Naturalist 27: $183-229$. https://ojs.lib.byu.edu/spc/index.php/wnan/article/download/30021/28484

Reveal, J.L. (1983) The Demoulin Rule and newly mandated combinations in Eriogonum (Polygonaceae). Taxon 32: 292-295. http://dx.doi.org/10.2307/1221986

Reveal, J.L. (2002) A review of Eriogonum corymbosum Benth. with emphasis on the species in southern Nevada. U.S. Fish and Wildlife Service, Las Vegas, $39 \mathrm{pp}$.

Reveal, J.L. (2004) New entities in Eriogonum (Polygonaceae: Eriogonoideae). Phytologia 86: 121-159.

Reveal, J.L. (2005) Eriogonum corymbosum Bentham in A. P. de Candolle and A. L. P. P. de Candolle, Prodr. 14: 17. 1856. In: Flora of North America North of Mexico, Vol. 5. Oxford University Press, New York, pp. 255-259. Available from: http://www.efloras.org/ florataxon.aspx?flora_id=1\&taxon_id=250060233.

Reveal, J.L. (2012) 11. Eriogonum Michx. Wild buckwheat. In: Holmgren, N.H., Holmgren, P.K. \& Reveal, J.L. (Eds.) Intermountain flora: Vascular plants of the Intermountain West, U.S.A. Volume Two, Part A Subclasses Magnoliidae-Caryophyllidae. The New York Botanical Garden Press, Bronx. pp. 269-273.

Reveal, J.L. (2013) Eriogonum manual for the Eriogonum Society. 2013 edition. Ithaca, New York: The Eriogonum Society, 1193 pp.

Reveal, J.L. (2014) Eriogonum manual for the Eriogonum Society. 2014 edition. Ithaca, New York: The Eriogonum Society, 1351 pp.

Riley, L., McGlaughlin, M.E. \& Helenurm, K. (2011) Microsatellite primers for the narrowly endemic shrub Eriogonum giganteum (Polygonaceae). American Journal of Botany Primer Notes \& Protocols in the Plant Sciences 98: e352-e355. http://dx.doi.org/10.3732/ajb.1100243

Stokes, S.G. (1936) The genus Eriogonum, a preliminary study based on geographical distribution. J.H. Neblett Press, San Francisco.

Thiers, B. (2011) Index herbariorum, a global directory of public herbaria and associated staff. New York Botanical Garden's Virtual Herbarium. Available from: http://sweetgum.nybg.org/ih/ (accessed 31 January 2015).

Vos, P., Hogers, R., Bleeker, M., Reijans, M., van de Lee, T., Hornes, M., Frijters, A., Pot, J., Peleman, J. \& Kuiper, M. (1995) AFLP: A new technique for DNA fingerprinting. Nucleic Acids Research 23: 4407-4414. http://www.ncbi.nlm.nih.gov/pmc/articles/PMC307397/

Watson, S. (1873) New Plants of Northern Arizona and the Region Adjacent. American Naturalist 7: 299-303. http://dx.doi.org/10.1086/271140

Watson, S. (1885) Contributions to American Botany. Proceedings of the American Academy of Arts and Sciences 20: 324-378. http://dx.doi.org/10.2307/25138775 